\title{
Clinical features of gingivostomatitis due to primary infection of herpes simplex virus in children
}

\author{
Chen-Wei Huang $^{1 \dagger}{ }^{,}$Chi-Hsien Hsieh ${ }^{1 \dagger}$, Ming-Ru Lin ${ }^{1,2}$ and Yhu-Chering Huang ${ }^{1,2^{*}}$
}

\begin{abstract}
Background: Primary herpetic gingivostomatitis (PHGS) in children, though usually self-limited, might mimic bacterial and enteroviral pharyngitis clinically. We conducted a study to define the clinical features of PHGS in children.
\end{abstract}

Methods: Between January 2012 and December 2016, 282 inpatients aged less than 19 years with cell cultureconfirmed herpes simplex virus (HSV) infection in a medical center were identified from the virologic laboratory logbook. Clinical data were retrospectively collected.

Results: Among the 282 inpatients, 185 cases were considered as PHGS and were included for analysis. Fever was present in $99.5 \%$. The mean duration of fever was 5.11 days ( \pm 2.24$)$ with the longest being 17 days. Common oral manifestations included oral ulcers (84.3\%), which equally resided in the anterior and posterior part of the oral cavity (65.4\% vs. 63.2\%), gum swelling and/or bleeding (67.6\%), and exudate coated tonsils (16.8\%). Leukocytosis (WBC count $>15,000 / \mathrm{uL}^{3}$ ) was noted in 52 patients (28.1\%) and a serum C-reactive protein level > $40 \mathrm{mg} / \mathrm{L}$ in 55 patients (29.7\%). Fixty-five patients (35\%) were diagnosed with PHGS on admission and were significantly more likely to have ulcers over the anterior oral cavity $(76.1 \%$ vs. $26.7 \%)$ and gum swelling/bleeding $(76.2 \%$ vs. $7.5 \%, p$-value all $<0.001)$ on admission and were significantly less likely to receive antibiotic treatment ( 16.9 vs. $36.7 \%, p$-value $<0.01$ ) than others. Forty-six patients (25\%) undiagnosed as PHGS on discharge were significantly more likely to have exudate coated on the tonsils, to receive antibiotic treatment and significantly less likely to have gum swelling/bleeding and oral ulcers (all $p$-values $<0.01$ ).

Conclusions: Meticulously identifying specific oral manifestations of gum swelling/bleeding and ulcers over the anterior oral cavity in children can help making the diagnosis of PHGS earlier and subsequently reduce unnecessary prescription of antibiotics.

Keywords: Herpes simplex virus, Primary herpetic gingivostomatitis, Children, Clinical manifestation

\footnotetext{
* Correspondence: ychuang@cgmh.org.tw

${ }^{\dagger}$ Chen-Wei Huang and Chi-Hsien Hsieh contributed equally to this work. 'Department of Medicine, Chang Gung University College of Medicine, Taoyuan, Taiwan

${ }^{2}$ Department of Pediatrics, Chang Gung Memorial Hospital, No.5, Fu-Hsin

Street, Kweishan, 333 Taoyuan, Taiwan
}

(c) The Author(s). 2020 Open Access This article is licensed under a Creative Commons Attribution 4.0 International License, which permits use, sharing, adaptation, distribution and reproduction in any medium or format, as long as you give appropriate credit to the original author(s) and the source, provide a link to the Creative Commons licence, and indicate if changes were made. The images or other third party material in this article are included in the article's Creative Commons licence, unless indicated otherwise in a credit line to the material. If material is not included in the article's Creative Commons licence and your intended use is not permitted by statutory regulation or exceeds the permitted use, you will need to obtain permission directly from the copyright holder. To view a copy of this licence, visit http://creativecommons.org/licenses/by/4.0/ The Creative Commons Public Domain Dedication waiver (http://creativecommons.org/publicdomain/zero/1.0/) applies to the data made available in this article, unless otherwise stated in a credit line to the data. 


\section{Background}

Herpes simplex virus (HSV) belongs to the alphaherpesviridae family, can be divided into two common pathogens, HSV-1 and HSV-2, and infects the humans [1-4]. Children infected with HSV may manifest many non-specific and systemic symptoms, including fever, headache, irritability, anorexia, and malaise. Many parents may attribute these symptoms to teething $[5,6]$. Among the HSV-infected related diseases in children, primary herpetic gingivostomatitis (PHGS) is the most representative clinical manifestation in a proportion of around $13-30 \%[7,8]$. Although PHGS is usually a selflimited disease, some severe systemic complications have been reported, such as central nervous system (CNS) dysfunction $[9,10]$.

In Taiwan, human non-polio enteroviruses (NPEVs) circulate in summer and fall seasons with an epidemic of enterovirus A71 (EV-A71) occurring every 3-4 years [11, 12]. In children with NPEV infection, EV-A71 is a more concerning issue since it may rapidly develop neurologic and systemic complications in a small percentage of patients [13]. The clinical symptoms/signs of enteroviral infection include high fever and oral ulcers, which are similar to initial presentations of PHGS and may lead to a clinical dilemma to differentiate these two infectious disease entities at the first glance. The misdiagnosis of NPEV infection from PHGS may sometimes lead to unnecessary medical costs due to hospitalization for close observation of dangerous signs of severe enteroviral infections. Moreover, the duration of symptoms induced by PHGS may be effectively shortened by acyclovir treatment given in the first $72-96 \mathrm{~h}$ of onset $[14,15]$. However, viral culture would usually take up to 2 weeks to confirm the diagnosis. Therefore, to clearly define the clinical features of PHGS in children would be important to make a precise diagnosis of these patients for the appropriate initial treatment.

\section{Methods}

\section{Ethics statement}

The study proposal was reviewed and approved by the Institutional Review Board of Chang Gung Memorial Hospital in 2017 (IRB No.201700757B0). Clinical information was collected and analyzed retrospectively and anonymously; therefore, an informed consent was waived.

\section{Study design and population}

We conducted this retrospective study in Chang Gung Memorial Hospital (CGMH), which provides from primary to tertiary care and is the largest tertiary medical center in Taiwan. In CGMH, clinical pediatricians would usually perform viral culture by obtaining a throat or nasopharynx swab for most inpatients with clinical suspicion of viral infection such as pharyngitis, upper and lower respiratory tract infection. During January 2012 and December 2016, inpatients aged less than 19 years with HSV identified in virus culture (from the virologic laboratory logbook) were enrolled. After excluding those who had $\geq$ two kinds of viruses identified or had positive bacterial culture, a total of 282 pediatric inpatients were included. Two medical students and one pediatrician reviewed their medical records retrospectively. Demographic data, clinical symptoms, laboratory results and clinical outcomes were collected and analyzed. Only those with oral manifestations such as pharyngitis, stomatitis (ulcers, vesicles, erosions) or gingivitis were considered as probable primary herpetic gingivostomatitis (PHGS) and included for final analysis.

\section{Viral isolation and identification}

The clinical specimens of throat swab, nasopharyngeal swab, sputum, bronchoalveolar lavage (BAL) or pleural effusion were inoculated into human embryonic lung cells (HEL), rhabdomyosarcoma cells (RD) and MadinDarby canine kidney cells (MDCK) while those of blood, cerebrospinal fluid (CSF), urine, stools or rectal swabs were inoculated into adenocarcinoma human alveolar basal epithelial cells (A549), monkey kidney cells (MK2), RD cells and HEL cells. Cultures were maintained in minimal essential media containing antibiotics, incubated at $33 \mathrm{C}$, and rotated at 12 revolutions per hour. The inoculated cell cultures were maintained and observed for the presence of cytopathic effects (CPE) for at least 4 weeks. Respiratory viruses, including human adenovirus (HAdV), human metapneumovirus, human parainfluenza virus types 1,2 , and 3 , influenza $A$ and $B$ viruses, Cytomegalovirus, HSV-1, HSV-2 and respiratory syncytial virus in CPE-positive cases were further identified by indirect immunofluorescence assay (IFA) with D3 Ultra DFA respiratory virus screening and identification kit (Diagnostic Hybrids, Inc., Athens, OH, USA). Anti-HSV 1 monoclonal antibody (ARGENE) react with cells infected with herpes simplex type 1 and display clear staining with Fluorescein (FITC)-conjugated AffiniPure Goat Anti-Mouse IgG + IgM (H + L) (Jackson).

\section{Definitions}

We classified the cases of probable PHGS into three groups, namely early diagnosis, late diagnosis and other diagnosis groups. Patients diagnosed with PHGS at the time of admission were classified as the Early Diagnosis group. Those diagnosed as other diseases at admission but eventually diagnosed with PHGS before discharge from the hospital were classified as the Late Diagnosis group. Those not diagnosed with PHGS throughout hospitalization were classified as the Other Diagnosis (than PHGS) groups. 
Clinical laboratory data on admission and the peak or nadir values during hospitalization were collected for analysis. We defined white blood cell count (WBC) above 15, $000 / \mu \mathrm{L}$ as leukocytosis while those below $5000 / \mu \mathrm{L}$ were defined as leukopenia. A platelet count above $450,000 / \mu \mathrm{L}$ was defined as thrombocytosis while that below 150,000/ $\mu \mathrm{L}$ were defined as thrombocytopenia. A serum creatinine (Cr) level above $1.0 \mathrm{mg} / \mathrm{dL}$ was considered to be renal function impairment while a 3-fold elevation of the normal values of aspartate aminotransferase (AST) and alanine aminotransferase (ALT) were considered to be elevated liver enzyme levels.

\section{Statistical analysis}

We used the Chi-square test or Fisher's exact test to compare categorical variables. Non-categorical variables were compared by one-way independent analysis of variance with post-hoc analysis. Data analyses were performed using SPSS software version 20.0 (SPSS Inc., Chicago, IL, USA). A $p$-value $<0.05$ was considered statistically significant.

\section{Results}

Of the 282 herpes simplex virus isolates, all were identified as herpes simplex virus type 1 (HSV-1). After excluding 97 cases without oral manifestations, a total of 185 probable cases of PHGS were included for final analysis. The specimens positive for HSV were obtained by throat swab $(182 / 185,98.4 \%)$, nasopharynx (1/185, $0.5 \%)$, and oral ulcer wound $(2 / 185,1 \%)$. Sixty-five patients (35\%) were diagnosed with PHGS at the time of admission (Early Diagnosis group), 74 patients were diagnosed during hospitalization (Late Diagnosis group) and 46 (25\%) patients were not diagnosed with PHGS throughout the hospitalization (Other Diagnosis group). Among the patients in Late and Other Diagnosis groups, most of the patients $(60 / 120,50 \%)$ were clinically diagnosed with herpangina or hand, foot, and mouth disease (HFMD) (due to enterovirus infection), followed by acute tonsillitis $(35.8 \%)$ at the time of admission. The detailed clinical diagnoses are listed in Table 1 . In the Late Diagnosis group, the mean interval from admission to the diagnosis of PHGS was $2.4 \pm 1.42$ days, with the longest of 6 days.

\section{Demographic and clinical characteristics}

Median age of the patients was 2 years, ranging from 7 months to 17 years. The mean age of children in the Other Diagnosis group was significantly older than those in the other two groups ( $p$-value $=0.005)$. Detailed clinical characteristics of the patients are shown in Table 1. All but one patients had fever and $77.3 \%$ had a fever higher than $39^{\circ} \mathrm{C}$. The mean duration of fever was 5.11 days and 39 patients (21\%) had a fever $>7$ days. Children in the Other Diagnosis group had a significantly shorter duration of fever than those in the other two groups ( $p$ value $=0.047)$.

Oral ulcer $(84.3 \%)$ was the most common oral manifestation, which was equally resided in the anterior and posterior oral cavity, followed by gum swelling or erythema and sore throat. The detailed oral manifestations stratified by the different time points of hospitalization are shown in Table 2. At the time of admission, children in the Early Diagnosis group were significantly more likely to have inflammation change over gingiva (76.2\%) and ulcers over the anterior part of oral cavity $(76.9 \%)$ than those in the other two groups (both $p$-value $<0.001$ ). During the course of hospitalization, oral manifestations increased significantly in children in the Late Diagnosis group and the differences of oral manifestations between the Early and Late Diagnosis groups became statistically insignificant. In contrast, compared with those in the other two groups, children in the Other Diagnosis group were significantly more likely to have exudate coated on the tonsils and significantly less likely to have gum swelling/ bleeding and oral ulcers (all $p$-value $<0.01$ ). Meanwhile, oral ulcers in the Other Diagnosis group tended to reside in the posterior oral cavity.

\section{Laboratory parameters}

Detailed laboratory data of the patients are shown in Table 3. Leukocytosis was noted in 52 (28.1\%) children and a serum CRP level of $\geq 40 \mathrm{mg} / \mathrm{L}$ (normal, $<5 \mathrm{mg} / \mathrm{L}$ ) was found in 55 (29\%) children. Seventeen patients (9.3\%) had a peak serum C-reactive protein (CRP) level > $100 \mathrm{mg} / \mathrm{L}$ (mimicking bacterial infection), with the highest being $193.09 \mathrm{mg} / \mathrm{L}$. None experienced renal function impairment and only three cases had an elevated aspartate aminotransferase level. There were no statistically significant differences among the three groups in terms of laboratory data. Among the children in the Other Diagnosis group, only 2 (4.3\%) patients had a final report of virus culture results before discharge from the hospital.

\section{Clinical outcomes and complications}

Forty-one (22.2\%) cases received antibiotics treatment for more than 3 days during the hospitalization. Compared with those in the other two groups, children in the Early Diagnosis group were significantly less likely to receive antibiotic treatment (16.9 vs. $36.7 \%, p$-value $=0.009)$. Half of the 185 cases received acyclovir treatment during hospitalization. The rate of acyclovir usage was significantly lower for patients in the Other Diagnosis group (2.2\%) than in the Late Diagnosis group (67.6\%), and in the Early Diagnosis group (64.6\%) (Table 1). No statistically significant difference was found between the children receiving and not receiving acyclovir treatment in terms of 
Table 1 Clinical features of 185 pediatric inpatients with culture-confirmed herpetic gingivostomatitis

\begin{tabular}{|c|c|c|c|c|c|}
\hline Characteristics & $\begin{array}{l}\text { Total } \\
\text { No. (\%) }\end{array}$ & $\begin{array}{l}\text { Late Diagnosis } \\
\text { No. (\%) }\end{array}$ & $\begin{array}{l}\text { Early Diagnosis } \\
\text { No. (\%) }\end{array}$ & $\begin{array}{l}\text { Other Diagnosis } \\
\text { No. (\%) }\end{array}$ & $P$-value \\
\hline Case Number & 185 & 74 & 65 & 46 & \\
\hline Gender & & & & & 0.053 \\
\hline Male & $92(49.7)$ & $33(44.6)$ & $29(44.6)$ & $30(65.2)$ & \\
\hline Female & $93(51.3)$ & $41(55.4)$ & $36(55.4)$ & $16(34.8)$ & \\
\hline Age, mean \pm SD $(\text { years })^{b}$ & $3.85 \pm 3.58$ & $3.23 \pm 3.01$ & $3.52 \pm 3.14$ & $5.33 \pm 4.57$ & 0.005 \\
\hline$<3$ years & $112(60.5)$ & $50(67.6)$ & $42(64.6)$ & $20(43.5)$ & 0.023 \\
\hline$>5$ years & $46(24.9)$ & 14 (18.9) & $17(26.2)$ & 15 (32.6) & 0.231 \\
\hline \multicolumn{6}{|l|}{ Diagnosis at admission } \\
\hline Herpangina/HFMD & $60(32.4)$ & $41(55.4)$ & NA & $19(41.3)$ & 0.241 \\
\hline Acute tonsillitis/pharyngitis & $43(23.3)$ & $21(28.4)$ & NA & $22(47.8)$ & 0.03 \\
\hline$\left.L R T\right|^{a}$ & $7(3.8)$ & $4(5.4)$ & NA & $3(6.5)$ & $>0.9$ \\
\hline FWLS & $3(1.6)$ & $3(4.1)$ & NA & 0 & 0.284 \\
\hline Others & $7(3.8)$ & $5(6.7)$ & NA & $2(4.4)$ & 0.706 \\
\hline \multicolumn{6}{|l|}{ Diagnosis at discharge } \\
\hline Herpangina/HFMD & $20(10.8)$ & NA & NA & $20(43.5)$ & NA \\
\hline Acute tonsillitis/pharyngitis & $22(11.9)$ & NA & NA & $22(47.8)$ & NA \\
\hline LRTI & $4(2.2)$ & NA & NA & $4(8.7)$ & NA \\
\hline Others & 0 & NA & NA & 0 & NA \\
\hline \multicolumn{6}{|l|}{ General symptoms } \\
\hline Fever & $184(99.5)$ & $74(100)$ & $64(98.5)$ & $46(100)$ & 0.395 \\
\hline Fever $>39^{\circ} \mathrm{C}$ & $133(77.3)$ & $53(79.1)$ & $44(74.6)$ & $36(78.3)$ & 0.819 \\
\hline Before admission (days) ${ }^{b}$ & $3.72 \pm 2.03$ & $3.45 \pm 2.01$ & $4.28 \pm 2.25$ & $3.34 \pm 1.55$ & 0.034 \\
\hline Duration, mean \pm SD (days) $[\text { Range }]^{\mathrm{b}}$ & $5.11 \pm 2.24[1-17]$ & $5.26 \pm 2.11[2-14]$ & $5.43 \pm 2.61[0-17]$ & $4.41 \pm 1.72[1-8]$ & 0.047 \\
\hline$>7$ days & $39(21.1)$ & $16(21.6)$ & $16(24.6)$ & $7(15.2)$ & 0.484 \\
\hline Decreased appetite & $176(95.1)$ & $72(97.3)$ & $63(96.9)$ & $41(89.1)$ & 0.092 \\
\hline Decreased activity & $131(70.8)$ & $55(74.3)$ & $42(64.6)$ & $34(73.9)$ & 0.394 \\
\hline Dehydration & $155(84.7)$ & $59(80.8)$ & $57(89.1)$ & $39(84.8)$ & 0.409 \\
\hline Mild & $142(91.6)$ & $56(94.9)$ & $54(94.7)$ & $32(82.1)$ & 0.045 \\
\hline Moderate & $13(8.4)$ & $3(5.1)$ & $3(5.3)$ & $7(17.9)$ & 0.045 \\
\hline \multicolumn{6}{|l|}{ Respiratory symptoms } \\
\hline Cough & $71(38.4)$ & $28(37.8)$ & $20(30.8)$ & $23(50)$ & 0.121 \\
\hline Rhinorrhea & $65(35.1)$ & $30(40.5)$ & $20(30.8)$ & $15(32.6)$ & 0.445 \\
\hline Nasal congestion & $16(8.6)$ & $7(9.5)$ & $4(6.2)$ & $5(10.9)$ & 0.650 \\
\hline Conjunctivitis & $4(2.2)$ & $2(2.7)$ & $1(1.5)$ & $1(2.2)$ & 0.892 \\
\hline \multicolumn{6}{|l|}{ Extra-pulmonary symptoms } \\
\hline Vomiting & $36(19.5)$ & $12(16.2)$ & $10(15.4)$ & $14(30.4)$ & 0.094 \\
\hline Diarrhea & $22(11.9)$ & $11(14.9)$ & $8(12.3)$ & $3(6.5)$ & 0.387 \\
\hline Abdominal pain & $14(7.6)$ & $10(13.5)$ & $1(1.6)$ & $3(6.5)$ & 0.027 \\
\hline Skin rash & $16(8.6)$ & $11(14.9)$ & $2(3.1)$ & $3(6.5)$ & 0.036 \\
\hline Trunk & $10(62.5)$ & $5(45.5)$ & $2(100)$ & $3(100)$ & 0.049 \\
\hline Extremities & $10(62.5)$ & $7(63.6)$ & $1(50)$ & $3(100)$ & 0.262 \\
\hline Face & $7(43.8)$ & $5(45.5)$ & $1(50)$ & $1(33.3)$ & 0.914 \\
\hline Whitlow & $1(6.3)$ & $1(9.1)$ & 0 & 0 & 0.677 \\
\hline
\end{tabular}


Table 1 Clinical features of 185 pediatric inpatients with culture-confirmed herpetic gingivostomatitis (Continued)

\begin{tabular}{|c|c|c|c|c|c|}
\hline Characteristics & $\begin{array}{l}\text { Total } \\
\text { No. (\%) }\end{array}$ & $\begin{array}{l}\text { Late Diagnosis } \\
\text { No. (\%) }\end{array}$ & $\begin{array}{l}\text { Early Diagnosis } \\
\text { No. (\%) }\end{array}$ & $\begin{array}{l}\text { Other Diagnosis } \\
\text { No. (\%) }\end{array}$ & $P$-value \\
\hline Complications & $4(2.2)$ & $2(1.4)$ & $2(4.7)$ & 0 & 0.159 \\
\hline CNS & 4 & 2 & 2 & 0 & 0.329 \\
\hline PICU admission & 4 & 2 & 2 & 0 & 0.159 \\
\hline Mortality & 0 & 0 & 0 & 0 & NA \\
\hline Antibiotics treatment ( $>3$ days) & $41(22.2)$ & $14(18.9)$ & $7(10.7)$ & $20(43.4)$ & $<0.001$ \\
\hline Acyclovir treatment & $93(50.3)$ & $50(67.6)$ & $42(64.6)$ & $1(2.2)$ & $<0.001$ \\
\hline LOS (days) ${ }^{b}$ & $4.54 \pm 1.92$ & $4.97 \pm 1.81$ & $4.26 \pm 2.15$ & $4.22 \pm 1.62$ & 0.039 \\
\hline
\end{tabular}

Abbreviations: HFMD Hand-foot-mouth disease, FWLS Fever without localizing sign, CNS Central nervous system, PICU Pediatric intensive care unit, LOS Length of hospital stay

${ }^{a}$ LRTI Lower respiratory tract infection, including pneumonia, bronchopneumonia and acute bronchiolitis

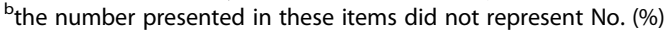

duration of fever $(5.20 \pm 2.38$ vs. $5.01 \pm 2.10, p$-value $=$ $0.295)$ and length of hospital stay $(4.76 \pm 2.06$ vs. $4.30 \pm$ $1.74, p$-value $=0.17$ ). Early usage of acyclovir within $72 \mathrm{~h}$ of disease onset did not have benefit in reducing the duration of fever or length of hospital stay, either (Table 4).
Four patients in this series had central nervous system (CNS) dysfunction (Table 1). An 18-month-old girl presented with status epilepticus for more than 30 min on day 2 of fever onset. One 7-year-7-month-old boy presented visual hallucinations on day 3 of fever onset. Both

Table 2 Detailed oral manifestations at different timelines of hospitalization

\begin{tabular}{|c|c|c|c|c|c|}
\hline Characteristics & $\begin{array}{l}\text { Total } \\
\text { No. (\%) }\end{array}$ & $\begin{array}{l}\text { Late Diagnosis } \\
\text { No. }(\%)\end{array}$ & $\begin{array}{l}\text { Early Diagnosis } \\
\text { No. }(\%)\end{array}$ & Other Diagnosis No. (\%) & $P$-value \\
\hline Case Number & 185 & 74 & 65 & 46 & \\
\hline \multicolumn{6}{|l|}{ Symptoms } \\
\hline Sore throat & $91(49.2)$ & $40(54.1)$ & $23(35.4)$ & $28(60.9)$ & 0.017 \\
\hline Drooling & $23(12.4)$ & $9(12.2)$ & $12(18.5)$ & $2(4.3)$ & 0.085 \\
\hline \multicolumn{6}{|l|}{ Signs } \\
\hline Ulcers & $156(84.3)$ & $69(93.2)$ & $61(93.8)$ & $26(56.5)$ & $<0.001$ \\
\hline Anterior oral cavity & $121(65.4)$ & $55(74.3)$ & $56(86.2)$ & $10(21.7)$ & $<0.001$ \\
\hline Posterior oral cavity & $117(63.2)$ & $56(75.7)$ & $36(55.4)$ & $25(54.3)$ & 0.016 \\
\hline Gum swelling/bleeding & $125(67.6)$ & $59(79.7)$ & $60(92.3)$ & $6(13.0)$ & $<0.001$ \\
\hline Exudate coated of tonsils & $31(16.8)$ & $12(16.2)$ & $4(6.2)$ & $15(32.6)$ & 0.001 \\
\hline \multicolumn{6}{|l|}{ On admission } \\
\hline \multicolumn{6}{|l|}{ Ulcers } \\
\hline Anterior oral cavity & $82(44.3)$ & $22(29.7)^{a}$ & $50(76.9)$ & $10(21.7)$ & $<0.001$ \\
\hline Posterior oral cavity & $102(55.1)$ & $45(60.8)$ & $33(50.8)$ & $24(52.2)$ & 0.443 \\
\hline Gum swelling/bleeding & $57(31.1)$ & $7(9.5)^{b}$ & $48(76.2)$ & $2(4.3)$ & $<0.001$ \\
\hline Exudate coating & $30(16.2)$ & $12(16.2)$ & $4(6.2)$ & $14(30.4)$ & 0.003 \\
\hline \multicolumn{6}{|l|}{ During hospitalization } \\
\hline \multicolumn{6}{|l|}{ Ulcers } \\
\hline Anterior oral cavity & $121(65.4)$ & $55(74.3)^{a}$ & $56(86.2)^{c}$ & $10(21.7)$ & $<0.001$ \\
\hline Posterior oral cavity & $117(63.2)$ & $56(75.7)$ & $36(55.4)$ & $25(54.3)$ & 0.016 \\
\hline Gum swelling/bleeding & $125(67.6)$ & $59(79.7)^{b}$ & $60(92.3)^{d}$ & $6(13.0)$ & $<0.001$ \\
\hline Exudate coating & 31 (16.8) & $12(16.2)$ & $4(6.2)$ & $15(32.6)$ & 0.001 \\
\hline
\end{tabular}

Within Late Diagnosis group, the percentage of ulcers over anterior oral cavity increased significantly during course of hospitalization ( $p$-value $<0.001$ ) ${ }^{b}$ Within Late Diagnosis group, the percentage of gum swelling or bleeding increased significantly during course of hospitalization ( $p$-value $\left.<0.001\right)$

${ }^{c}$ The difference of percentage of ulcers over the anterior oral cavity between the Early and Late Diagnosis group became insignificant during the course of hospitalization ( $p$-value $=0.09$ )

${ }^{\mathrm{d}}$ The difference of percentage of gum swelling/bleeding between the Early and Late Diagnosis group became insignificant during the course of hospitalization $(p$-value $=0.051$ ) 
Table 3 Laboratory findings of 185 inpatients with culture confirmed herpetic gingivostomatitis

\begin{tabular}{|c|c|c|c|c|c|}
\hline Laboratory data & Total & Late Diagnosis & Early Diagnosis & Other Diagnosis & $P$-value \\
\hline Case Number & 185 & 74 & 65 & 46 & \\
\hline \multicolumn{6}{|l|}{ Hemogram } \\
\hline WBC count $(1000 / \mu \mathrm{L})^{\mathrm{a}}$ & $12.44 \pm 4.95$ & $13.05 \pm 5.35$ & $12.43 \pm 4.77$ & $11.46 \pm 4.44$ & 0.229 \\
\hline WBC count-peak ${ }^{\mathrm{b}}$ & $12.47 \pm 4.89$ & $13.12 \pm 5.31$ & $12.41 \pm 4.65$ & $11.49 \pm 4.4$ & 0.209 \\
\hline WBC count-nadir & $10.64 \pm 4.01$ & $10.96 \pm 3.70$ & $10.98 \pm 4.05$ & $9.62 \pm 4.34$ & 0.147 \\
\hline$<5000 / \mu \mathrm{L}($ No. $(\%))$ & $6(3.2)$ & $1(1.4)$ & $2(3.1)$ & $3(6.5)$ & 0.315 \\
\hline$>15,000 /$ L (No. (\%)) & $52(28.1)$ & $23(31.1)$ & $19(29.2)$ & $10(21.7)$ & 0.525 \\
\hline 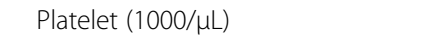 & $251.72 \pm 73.0$ & $260.57 \pm 66.42$ & $253.25 \pm 64.26$ & $235.37 \pm 91.25$ & 0.181 \\
\hline$<150,000 / \mu \mathrm{L}$ (No. (\%)) & $10(5.4)$ & $3(4.1)$ & $2(3.1)$ & $5(10.9)$ & 0.167 \\
\hline 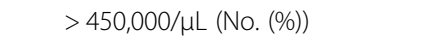 & $4(2.2)$ & $1(1.4)$ & 0 & $3(6.5)$ & 0.057 \\
\hline \multicolumn{6}{|l|}{ Biochemistry } \\
\hline $\mathrm{CRP}(\mathrm{mg} / \mathrm{L})^{\mathrm{a}}$ & $40.31 \pm 37.47$ & $40.00 \pm 40.24$ & $35.52 \pm 34.68$ & $47.48 \pm 36.31$ & 0.256 \\
\hline CRP-peak (mg/L) ${ }^{\mathrm{b}}$ [Range] & $\begin{array}{l}41.86 \pm 38.15 \\
{[1.3-193.09]}\end{array}$ & $\begin{array}{l}40.51 \pm 40.01 \\
{[2.1-193.09]}\end{array}$ & $\begin{array}{l}37.78 \pm 36.73 \\
{[1.3-165.97]}\end{array}$ & $\begin{array}{l}49.7 \pm 36.7 \\
{[1.4-132.7]}\end{array}$ & 0.252 \\
\hline$<40$ mg/L (No. (\%)) & $130(71.0)$ & $51(69.9)$ & $48(75)$ & $31(67.4)$ & 0.659 \\
\hline$>100$ mg/L (No. (\%)) & $17(9.3)$ & $8(11.0)$ & $4(6.2)$ & $5(10.9)$ & 0.564 \\
\hline BUN (mg/dL) & $8.8 \pm 2.83$ & $9.05 \pm 3.09$ & $8.67 \pm 2.26$ & $8.61 \pm 3.07$ & 0.876 \\
\hline $\mathrm{Cr}(\mathrm{mg} / \mathrm{dL})$ & $0.14 \pm 0.35$ & $0.07 \pm 0.25$ & $0.08 \pm 0.28$ & $0.31 \pm 0.47$ & 0.006 \\
\hline$>1.0$ mg/dL (No. (\%)) & 0 & 0 & 0 & 0 & NA \\
\hline AST (U/L) [Range] & $\begin{array}{l}38.39 \pm 42.1 \\
{[15-434]}\end{array}$ & $\begin{array}{l}44.18 \pm 56.49 \\
{[16-434]}\end{array}$ & $\begin{array}{l}32.4 \pm 8.72 \\
{[17-58]}\end{array}$ & $\begin{array}{l}41.00 \pm 40.62 \\
{[15-246]}\end{array}$ & 0.369 \\
\hline > 3-folds normal value (No. (\%)) & $3(2.6)$ & $2(3.6)$ & 0 & $1(6.2)$ & 0.32 \\
\hline Sugar (mg/dL) & $94.61 \pm 33.46$ & $90.07 \pm 15.31$ & $89.36 \pm 16.84$ & $108.5 \pm 58.88$ & 0.06 \\
\hline Hypoglycemia (<60) (No. (\%)) & $1(1.2)$ & $1(2.5)$ & 0 & 0 & 0.603 \\
\hline
\end{tabular}

${ }^{\mathrm{a}}$ First laboratory exam on admission

${ }^{\mathrm{b}}$ The highest or lowest laboratory value during hospitalization

Abbreviations: WBC White blood cell, $\mathrm{Hb}$ Hemoglobin, CRP C-reactive protein, BUN Blood urea nitrogen, $\mathrm{Cr}$ Creatinine, AST Aspartate aminotransferase

of them were considered as encephalitis/encephalopathy due to enterovirus infection initially. Magnetic Resonance Imaging (MRI) was performed on them and there were no documented abnormal findings. The other 2 cases were diagnosed with PHGS at the time of admission but presented symptoms of CNS dysfunction during hospitalization. The first one was an 11-year-old boy who developed conscious disturbance later and the second one was a 2-year-old girl who had frequent seizure

Table 4 Effectiveness of acyclovir treatment between different time points

\begin{tabular}{lllll}
\hline & $<\mathbf{7 2} \mathbf{~ h}$ & $\mathbf{> 7 2} \mathbf{~ h}$ & Not used & $P$-value \\
\cline { 2 - 5 } Case number (\%) & $43(23.2)$ & $51(27.6)$ & $91(49.2)$ & \\
Fever duration (days) & $5.21 \pm 2.82$ & $5.24 \pm 1.96$ & $4.99 \pm 2.11$ & 0.778 \\
LOS (days)* & $4.58 \pm 2.32$ & $4.96 \pm 1.82$ & $4.27 \pm 1.73$ & 0.121 \\
\hline
\end{tabular}

"Length of hospital stay attacks on day 5 of disease onset. Electroencephalogram (EEG) examination was performed in all of them, but none had abnormal focal epileptic form discharge. Only one case received spinal tapping, and cerebrospinal fluid studies showed no pleocytosis and negative for HSV by polymerase chain reaction and viral culture. None of them died, had neurologic sequelae and required long term usage of anticonvulsants.

\section{Discussion}

Results from this study showed that fever remained the most common clinical symptom in children with PHGS. The duration of fever in children with other virusinduced diseases usually ranged from two to 4 days, while children with PHGS would suffer for a longer fever duration $[16,17]$. In this study, the average fever duration was 5 days and more than $20 \%$ of the patients even had a fever duration longer than 7 days. 
In this series, only $35 \%$ of the cases were diagnosed with PHGS at the time of admission. Most of the cases not diagnosed early were considered to be herpangina/ HFMD (due to enteroviral infection) initially. In general pediatric practice, it is believed that HSV-related infection would cause vesicles and/or ulcers in the perioral region and anterior oral cavity [18-20]. On the contrary, the oral lesions of herpangina and HFMD typically located at the posterior oral cavity region, such as the anterior pillars of the fauces, soft palate, tonsils, and uvula, presented as hyperemic vesicles and/or ulcers. However, coxsackievirus A6, a specific serotype of enterovirus, could result in so-called atypical HFMD with clinical manifestations of perioral vesicles and more devastating skin lesions such as onychomadesis and even StevensJohnson syndrome since 2008 [21, 22]. In this series, we found the oral ulcers in PHGS could be equally resided in both the anterior and posterior parts of oral cavity. Compared with the patients in the Early Diagnosis group, the patients in both the Late and Other Diagnosis groups had a significantly lower rate of the presentation of both stomatitis lesions over the anterior oral cavity and gingivitis at the time of admission. The presentation of both lesions reached a comparable rate during hospitalization in the patients in the Late Diagnosis group while still significantly lower in the patients in Other Diagnosis group. These findings suggest that both the stomatitis lesions over the anterior part of the oral cavity and gingivitis are key features for a clinical diagnosis of PHGS. A case of PHGS may manifest stomatitis lesions over the posterior part of the oral cavity first, which may be misdiagnosed as herpangina caused by enterovirus, and then the stomatitis lesions may extend to the anterior part of oral cavity and the presentation of gingivitis may occur, which leads to the diagnosis of PHGS. For those without the presentation of both lesions, a clinical diagnosis of PHGS would be not considered and not made on most occasions. It is not impossible that some cases might indeed present both lesions but were missed by the clinicians and subsequently undiagnosed.

Only a few cases of PHGS in this series had complications such as CNS dysfunction, compared to certain serotype of enterovirus, such as enterovirus D68 and enterovirus A71, which may lead to fatal viral meningitis or encephalitis and result in limb paralysis or mortality [23, 24].

C-reactive protein (CRP), a laboratory test, is often used as a reference biomarker to distinguish bacterial (higher level) from viral (lower level) infections, though inconclusively. Nevet et al [25] reported that a high value of CRP was commonly seen in pediatric patients with PHGS and the average value of 66 patients in their study was up to $74 \mathrm{mg} / \mathrm{L}$, with more than one-third of the patients having a value $>70 \mathrm{mg} / \mathrm{L}$. In the current study, along with leukocytosis, a higher serum CRP level $>40 \mathrm{mg} / \mathrm{L}$ (normal, $<5 \mathrm{mg} / \mathrm{L}$ ) was found in around $30 \%$ of the cases. High values of CRP are prevalent in patients with primary herpetic gingivostomatitis, similar to adenoviral infections and some bacterial infections. In contrast, for enteroviral infection, a retrospective study including 3566 children with a diagnosis of either herpangina or HFMD in Taiwan revealed that three quarters of the cases had a CRP level $<40 \mathrm{mg} / \mathrm{L}$ while only $6 \%$ cases had a CRP level $>80 \mathrm{mg} / \mathrm{L}$ [26]. CRP levels in patients infected with different serotypes of enteroviruses may vary from a normal level to a higher level. For example, an average CRP level was $9 \mathrm{mg} / \mathrm{L}$ for children with enterovirus-A71 infection while the average level was up to $77 \mathrm{mg} / \mathrm{L}$ for children infected with coxsackievirus A2 [27]. Other studies also showed the different CRP levels in children infected with different enterovirus serotypes [21, 28-30]. These findings suggest that a CRP level is not reliable to distinguish PHGS from both bacterial and enteroviral pharyngitis.

Some studies indicated that administration of oral acyclovir within 72 to $96 \mathrm{~h}$ after disease onset can effectively reduce the duration of fever, oral ulcers, and food intake difficulty in children with PHGS [31-33]. Half of the cases in this study received acyclovir treatment. However, the administration of acyclovir treatment, whether within $72 \mathrm{~h}$ of fever onset or not, had no significant beneficial influence on either the duration of fever or the length of hospital stay. Since this was a retrospective study, the exact timing and dosing of acyclovir therapy as well as the healing of oral ulcers and the amount of food intake might not be meticulously evaluated and recorded and subsequently led to a negative result of the effect of acyclovir therapy.

In this series, 41 (22.2\%) patients, especially those in the Other Diagnosis group, received antibiotic treatment for more than 3 days during hospitalization, though there was no evidence of bacterial infection. Again, judicious usage of antibiotics cannot be overemphasized. Recognizing that children with PHGS may manifest prolonged high fever, leukocytosis, and a high serum CRP level that mimics bacterial infections may help clinicians to avoid the unnecessary prescription of antibiotics.

There are several limitations in this study. First, as a retrospective study, there were "inherent" drawbacks. Not all clinical information and laboratory data could be collected by chart review and some confounding bias could not be avoided due to different judgments of clinical physicians. Second, we did not check serum IgG and IgM against HSV, which can distinguish primary infection from reactivation. However, in this study, we tried to identify and include PHGS cases for final analysis as possibly as we can. Because most primary HSV-1 
infection presents with oral manifestations [34, 35], we excluded 97 cases without oral manifestations, who accounted for more than one-third of the initial HSVpositive patients and might be probable HSV-reactivated cases, for final analysis. Third, we already excluded those co-infected with other bacteria and viruses; however, throat swab for group A streptococcus was not performed for each case to exclude the possibility of such infection and the possibility of co-infection with other viruses could not be totally excluded. Since only virus isolation using tissue culture was applied in this study, the viruses which cannot present CPE in the selected cell lines, such as coronavirus, human metapneumovirus, human bocavirus etc., would be missed. This could explain that there were still some cases present with symptoms of upper respiratory tract infection in this study.

\section{Conclusions}

Clinically, a case of primary herpetic gingivostomatitis may manifest stomatitis lesions over the posterior part of the oral cavity first, and then the lesions may extend to the anterior part of the oral cavity with the presentation of gingivitis (as gum swelling/bleeding), which are key features for a clinical diagnosis of PHGS. Meticulously identifying these specific oral manifestations can help make the diagnosis of PHGS earlier and subsequently reduce unnecessary prescription of antibiotics.

\section{Abbreviations}

HSV: Herpes simplex virus; PHGS: Primary herpetic gingivostomatitis; CRP: Creactive protein; HFMD: Hand, foot and mouth disease; CNS: Central nervous system

\section{Acknowledgements}

Not applicable.

\section{Authors' contributions}

$\mathrm{CWH}, \mathrm{CHH}, \mathrm{YCH}$ : Study design, Data collection, Data analysis, Writing. MRL: Data analysis, Modification of writing. The authors read and approved the final manuscript.

\section{Funding}

The study was supported by a grant from Chang Gung Memorial Hospital (CMRPG3H1291). The funders had no role in the study design, data collection and analysis, decision to publish, or preparation of the manuscript.

\section{Availability of data and materials}

The datasets used and/or analysed during the current study are available from the corresponding author on reasonable request.

\section{Ethics approval and consent to participate}

The study was approved by the institutional review board of Chang Gung Memorial Hospital and a written informed consent was waived due to the retrospective chart review. The data used in this study was anonymised before its use.

\section{Consent for publication}

Not applicable.

\section{Competing interests}

The authors have no conflicts of interest relevant to this article to disclose.
Received: 14 April 2020 Accepted: 12 October 2020

Published online: 20 October 2020

\section{References}

1. Kolokotronis A, Doumas S. Herpes simplex virus infection, with particular reference to the progression and complications of primary herpetic gingivostomatitis. Clin Microbiol Infect. 2006;12:202-11.

2. Stanberry LR, Floyd-Reising SA, Connelly BL, Alter SJ, Gilchrist MJ, Rubio C, et al. Herpes simplex viremia: report of eight pediatric cases and review of the literature. Clin Infect Dis. 1994;18:401-7.

3. Chong EM, Wilhelmus KR, Matoba AY, Jones DB, Coats DK, Paysse EA. Herpes simplex virus keratitis in children. Am J Ophthalmol. 2004;138:474-5.

4. Nahmias AJ, Roizman B. Infection with herpes-simplex viruses 1 and 2. N Engl J Med. 1973;289:667-74

5. Saksena MM, Wakisaka H, Tijono B, Boadle RA, Rixon F, Takahashi $H$, et al. Herpes simplex virus type 1 accumulation, envelopment, and exit in growth cones and varicosities in mid-distal regions of axons. J Virol. 2006;80:3592-606.

6. Cunningham AL, Taylor R, Taylor J, Marks C, Shaw J, Mindel A, et al. Prevalence of infection with herpes simplex virus types 1 and 2 in Australia: a nationwide population based survey. Sex Transm Infect. 2006;82:164-8.

7. Amir J, Harel L, Smetana Z, Varsano I. The natural history of primary herpes simplex type 1 gingivostomatitis in children. Pediatr Dermatol. 1999;16:259-63.

8. Whitley RJ, Roizman B. Herpes simplex virus infections. Lancet. 2001;357: 1513-8

9. Kidokoro H, de Vries LS, Ogawa C, Ito Y, Ohno A, Groenendaal F, et al. Predominant area of brain lesions in neonates with herpes simplex encephalitis. J Perinatol. 2017;37:1210-4

10. Shukla B, de Vries LS, Ogawa C, Ito Y, Ohno A, Groenendaal F, et al. Aseptic meningitis in adults and children: diagnostic and management challenges. J Clin Virol. 2017:94:110-4.

11. Ho M, Chen ER, Hsu KH, Twu SJ, Chen KT, Tsai S, et al. An epidemic of. Enterovirus 71 infection in Taiwan. Taiwan Enterovirus epidemic working group. N Engl J Med. 1999;341:929-35.

12. Liu DP, Wang TA, Huang WT, Chang LY, Wang ET, Cheng SH, et al. Disease burden of enterovirus infection in Taiwan: implications for vaccination policy. Vaccine. 2016;34:974-80.

13. Ooi MH, Wong SC, Lewthwaite P, Cardosa MJ, Solomon T. Clinical features, diagnosis, and management of enterovirus 71. Lancet Neurol. 2010;9:1097-105.

14. Chaudhary B, Verma S. Preparation and evaluation of novel in situ gels containing acyclovir for the treatment of oral herpes simplex virus infections. Sci World J. 2014;2014:280928.

15. Goldman RD. Acyclovir for herpetic gingivostomatitis in children. Can Fam Physician. 2016;62:403-4.

16. Kuzushima K, Kimura H, Kino Y, Kido S, Hanada N, Shibata M, et al. Clinical manifestations of primary herpes simplex virus type 1 infection in a closed community. Pediatrics. 1991;87:152-8

17. King DL, Steinhauer W, García-Godoy F, Elkins CJ. Herpetic gingivostomatitis and teething difficulty in infants. Pediatr Dent. 1992;14:82-5.

18. Arduino PG, Porter SR. Herpes simplex virus type 1 infection: overview on relevant clinico-pathological features. J Oral Pathol Med. 2008;37:107-21.

19. Rodu B, Mattingly G. Oral mucosal ulcers: diagnosis and management. J Am Dent Assoc. 1992;123:83-6.

20. Faden $\mathrm{H}$. Management of primary herpetic gingivostomatitis in young children. Pediatr Emerg Care. 2006;22:268-9.

21. Lo SH, Huang YC, Huang CG, Tsao KC, Li WC, Hsieh YC, et al. Clinical and epidemiologic features of Coxsackievirus A6 infection in children in northern Taiwan between 2004 and 2009. J Microbiol Immunol Infect. 2011. 44:252-7.

22. Ramirez-Fort MK, Downing C, Doan HQ, Benoist F, Oberste MS, Khan F, et al. Coxsackievirus A6 associated hand, foot and mouth disease in adults: clinical presentation and review of the literature. J Clin Virol. 2014;60:381-6.

23. Rhoades RE, Tabor-Godwin JM, Tsueng G, Feuer R. Enterovirus infections of the central nervous system. Virology. 2011;411:288-305.

24. Michos AG, Syriopoulou VP, Hadjichristodoulou C, Daikos GL, Lagona E, Douridas $P$, et al. Aseptic meningitis in children: analysis of 506 cases. PLoS One. 2007;2:e674.

25. Nevet A, Yarden-Bilavsky H, Ashkenazi S, Livni G. C-reactive protein level in children with primary herpetic gingivostomatitis. Isr Med Assoc J. 2014;16: $700-2$. 
26. Kuo KC, Huang YH, Chen IL, Huang YC, Li CC, Kuo HC, et al. Are antibiotics beneficial to children suffering from enterovirus infection complicated with a high C-reactive protein level? Inter J Inf Dis. 2014;25:100-3.

27. Chen SP, Huang YC, Li WC, Chiu CH, Huang CG, Tsao KC, et al. Comparison of clinical features between coxsackievirus $\mathrm{A} 2$ and enterovirus 71 during the enterovirus outbreak in Taiwan, 2008: a children's hospital experience. J Microbiol Immunol Infect. 2010;43:99-104.

28. Lee HY, Chen CJ, Huang YC, Li WC, Chiu CH, Huang CG, et al. Clinical features of echovirus 6 and 9 infections in children. J Clin Virol. 2010;49:175-9.

29. Chen YJ, Huang YC, Huang CG, Tsao KC, Li WC, Hsieh YC, et al. Comparative genomic analysis of coxsackievirus A6 strains of different clinical disease entities. PLoS One. 2012;7:e52432.

30. Lee CJ, Huang YC, Yang S, Tsao KC, Chen CJ, Hsieh YC, et al. Clinical features of coxsackievirus A4, B3 and B4 infections in children. PLoS One. 2014;9: e87391.

31. Amir J, Harel L, Smetana Z, Varsano I. Treatment of herpes simplex gingivostomatitis with aciclovir in children: a randomised double blind placebo controlled study. BMJ. 1997;314:1800-3.

32. Hudson B, Powell C. Towards evidence based medicine for paediatricians. Does oral aciclovir improve clinical outcome in immunocompetent children with primary herpes simplex gingivostomatitis? Arch Dis Child. 2009;94:165-7.

33. Cataldo F, Violante M, Maltese I, Traverso G, Paternostro D. Herpetic gingivostomatitis in children: the clinico-epidemiological aspects and findings with acyclovir treatment. A report of the cases of 162 patients. Pediatr Med Chir. 1993;15:193-5.

34. Cesario TC, Poland JD, Wulff H, Chin TDY, Wenner HA. Six years' experience with herpes simplex virus in a children's home. Am J Epidemiol. 1969;90: 416-22.

35. Schmitt DL, Johnson DW, Henderson FW. Herpes simplex type 1 infection in group day care. Pediatr Infect Dis J. 1991;10:729-34.

\section{Publisher's Note}

Springer Nature remains neutral with regard to jurisdictional claims in published maps and institutional affiliations.

Ready to submit your research? Choose BMC and benefit from:

- fast, convenient online submission

- thorough peer review by experienced researchers in your field

- rapid publication on acceptance

- support for research data, including large and complex data types

- gold Open Access which fosters wider collaboration and increased citations

- maximum visibility for your research: over $100 \mathrm{M}$ website views per year

At $\mathrm{BMC}$, research is always in progress.

Learn more biomedcentral.com/submissions 